\title{
ADVERSE EFFECTS ASSOCIATED WITH SULFASALAZINE ON CHRONIC PLAQUE TYPE PSORIASIS
}

\author{
KHONDKER L ${ }^{1}$, HAZRA SC ${ }^{2}$, MAHMUD MM ${ }^{3}$, KHAN MSI $^{4}$, HOSSAIN MS ${ }^{5}$
}

\begin{abstract}
:
A prospective, randomized controlled clinical trial was conducted with thirty patients of chronic plaque psoriasis to evaluate the adverse effects of sulfasalazine on chronic plaque type psoriasis, comparing with methotrexate. Fifteen respondents (Group A) were treated with oral Sulfasalazine (Reumazin 500mg) 2 gram in 2 divided doses. Equal number of psoriatics (Group B) was treated with $7.5 \mathrm{mg}$ of methotrexate (Methotrax $2.5 \mathrm{mg}$ tablet) once weekly at night for 8 weeks. Psoriasis area and severity index PASI score was calculated as main out come measure at entry level and follow up after four weeks and 8 weeks (final follow up). Physical examination, complete blood count, serum alanine transaminases (ALT) and creatinine level were tested at baseline and at every follow up. Statistically significant improvement of psoriasis based on PASI score reduction was observed after eight weeks of treatment in both groups $(p<0.001)$. Adverse effects were noticed in $73.3 \%$ and $66.7 \%$ in group $A$ and $B$ respectively but that were common and mild to moderate in severity and did not require withdrawal of therapy and no significant difference was found in two groups (P value>0.05). There was no significant change in hematological and biochemical tests at baseline and follow up between two groups ( $P$ value $>0.05$ ). In conclusion, sulfasalazine is a safe alternative therapy for chronic plaque type psoriasis in comparable with methotrexate.
\end{abstract}

Key words: Adverse effects with sulfasalazine, methotrexate, plaque type psoriasis, psoriasis.

J Dhaka Med Coll. 2012; 21(1) : 28-36.

\section{Introduction:}

Psoriasis is a common, genetically determined, inflammatory skin disorder of unknown cause, which, in its most usual form, is characterized by well demarcated, raised, red scaling patches that preferentially localize to the extensor surfaces. ${ }^{1}$

Sulfasalazine consists of 5-aminosalicylic acid (5-ASA) and sulfapyridine (SP), linked by an azo bond.Thus, sulfasalazine and 5-ASA inhibit cyclooxygenase and 5-lipoxygenase. ${ }^{2,3}$ Sulfasalazine and SP, but not 5-ASA, have been also shown to inhibit Ag-stimulated TNF- $\alpha$ production by mast cells. Other studies showed that sulfasalazine, but not 5-ASA and SP, is anti-inflammatory in the murine air pouch model of inflammation. ${ }^{4}$

Patients with moderate to severe disease generally require phototherapy (e.g. narrow band ultraviolet $B$ radiation), photo chemotherapy (oral psoralen plus ultraviolet A radiation) or systemic agents (e.g. Cyclosporine, methotrexate, oral retinoids, fumaric acid esters) to control their disease adequately. In general, these therapeutic modalities have proven to be highly effective in the treatment of psoriasis. However, potentially serious toxicities can limit their long-term use. There is no standard therapeutic approach for patients with moderate to severe psoriasis, the benefits and risks of phototherapy, photo chemotherapy and systemic therapy must be weighed carefully for each patient, and treatment should be individualized accordingly. ${ }^{5}$

The most common side effects include nausea, headache and indigestion. These are usually mild and self limiting. ${ }^{6}$ If the safety of

1. Dr. Lubna Khondker, Assistant Professor, department of Dermatology and Venereology, Bangabandhu Sheikh Mujib Medical University, Dhaka.

2. Dr. Samaresh Chandra Hazra, Medical officer, Infectious Disease Hospital, Dhaka, E-mail: samohazra@yahoo.com

3. Dr. Md. Mostaque Mahmud, Registrar, Shaheed Sohrawardy Medical College Hospital, E-mail: drmstq@yahoo.com

4. Major (Dr.) Md Shirajul Islam Khan, Specialist in Dermatology, Combined Military Hospital (CMH), Dhaka

5. Dr. Md. Shahadat Hossain, Assistant Prfessor, Department of Physical Medicine, Dhaka Medical College Correspondence : Dr. Samaresh Chandra Hazra, Medical officer, Infectious Disease Hospital, Dhaka, E-mail: samohazra@yahoo.com 
sulfasalazine is found equal to better than methotrexate, it can be used as a monotherapy or as an effective pair in combination therapy or rotational therapy. The potential toxic effects of long term use of the classic anti-psoriatics, long continuous therapy, higher cost and low socio-economic conditions of patients justify a clinical trial with sulfasalazine in Bangladesh. We carried out this clinical trial to explore the safety of sulfasalazine, as a new option to treat psoriasis.

\section{Material and Methods:}

A prospective, randomized controlled clinical trial study was carried out with thirty clinically and histopathologicaly diagnosed patients of chronic plaque psoriasis. The study conducted in the department of Dermatology and Venereology, Bangabandhu Sheikh Mujib Medical University (BSMMU), Dhaka for duration of April 2010 to May 2011. Sampling technique was simple random sampling and data were collected in a predesigned questionnaire.

Inclusion Criteria are: all patients reported with chronic plaque type psoriasis, in the department of Dermatology and venereology of BSMMU, Dhaka during the study period, Psoriasis Area And Severity Index (PASI) ${ }^{37}$ (moderate to severe type), female who agreed to practice appropriate contraceptive measure and patients having serum alanine transaminase(ALT) and serum creatinine level within normal limit.

Exclusion Criterias are: Patients not willing to participate in the study, pregnant and lactating females, persons working under direct sunlight, persons having hypersensitivity to methotrexate, sulfasalazine or any sulfa drugs and salicylates, individuals on any form of topical or oral medication for at least 2 weeks prior to the study and person having impairment of renal, hepatic, hematological system and history of acute or chronic active infections.

\section{Procedure of data collection:}

A total number of thirty patients were randomely selected into two groups (group-A and group-B), each of which included 15 patients. Complete history, general physical and dermatological examinations were done for all enrolled patients. For women of reproductive age reproductive history, menstrual history, lactation and pregnancy plan were carefully judged. History and physical findings were recorded in a data sheet. Baseline investigations included complete blood count (total count, differential count of white blood cell, platelet count, $\mathrm{Hb} \%$, ESR), urine analysis, serum creatinine, serum alanine transaminase, random blood sugar, $\mathrm{x}$-ray chest posterior-anterior view and pregnancy test as required, were done. Finally those patients, who matched the inclusion and exclusion criteria according to history, physical examination and laboratory reports and freely gave their informed consent, were selected for the study. Photographs of all lesions at baseline and at the end of $4^{\text {th }}$ and $8^{\text {th }}$ week were taken for subsequent assessment and further comparison. Erythema, induration and scaling were recorded in term of PASI (Psoriasis Area and Severity Index) at baseline, after four weeks and $8^{\text {th }}$ weeks of therapy as the tool of main outcome measure. Adverse effects of the drugs among all patients of two groups were noted.

\section{Initiation of therapy of methotrexate:}

Premethotrexate screening

Premethotexate history and physical examination includes: History of presence of hepatotoxic risk factors- significant life-time alcohol consumption/Past or current use of $>1$ 2 drinks per day; persistently abnormal liver function tests, inherited or acquired liver disease, chronic hepatitis B or C, obesity, diabetes mellitus, exposure to hepatotoxic drugs or chemicals. Child bearing female-desiring to be pregnant, pregnant, nursing. Renal insufficiency- severe renal insufficiency or on dialysis. History of haematological abnormalities. History of drug. Physical examinations include signs of cirrhosis/renal insufficiency/ pregnancy.

\section{Scoring of psoriasis:}

Severity of psoriasis were scored by using psoriasis area and severity index PASI formula, in which the body was divided into four areas 
Head (H), Upper limb (U), Trunk (T) and Lower limb (L). Erythema (E), Induration (I) and Desquamation (D) were measured for each area with a scale ranging zero (none), 1 (mild), 2 (moderate), 3 (severe) and 4 (very severe). Erythema and induration were measured as visual impression and palpation of the lesion in place of ideal chromometer and ultrasound respectively. Body surface was measured with Patients' palm, taken as $1 \%$ total body surface area. Head area: one palmer surface of hand = $10 \%$ of head area;Upper limb: two palmer surface of hand $=10 \%$ upper limb area;Trunk area: three palmer surface of hand $=10 \%$ trunk area;Lower limb: four palmer surface of hand = $10 \%$ lower limb area. PASI was calculated using the following formula:

$0.1\left(E_{H}+I_{H}+D_{H}\right) A_{H}+0.2\left(E_{U}+I_{U}+D_{U}\right) A_{U}+0.3$ $\left(\mathrm{E}_{\mathrm{T}}+\mathrm{I}_{\mathrm{T}}+\mathrm{D}_{\mathrm{T}}\right) \mathrm{A}_{\mathrm{T}}+$

$0.4\left(E_{L}+I_{L}+D_{L}\right) A_{L}$ (Feldman \& Krueger, 2005).

Severity of plaque type psoriasis can be classified according to PASI score (Schmitt \& Wozel, 2005). Psoriasis can be defined as severe when PASI score $>12$, moderate when PASI score 7-12 and mild when PASI score $<7$. Percentage of PASI score reduction is used for assessment the efficacy of drug and prognosis of plaque type psoriasis. The percentage of PASI score reduction can be describe as 4 grades. When PASI reduction $<50 \%$ it can be defined as minimal response, $50 \%-69 \%$ as moderate response, $70 \%-89 \%$ as very good response and 90-100\% as excellent response.

\section{Intervention of Sulfasalazine:}

Randomly 15 patients of psoriasis were included in sulfasalazine (group A) and another 15 were included in methotrexate group (B control). All patients of Group-A were treated with tablet Sulfasalazine ( Reumazin $500 \mathrm{mg}$ ) at a dose of $500 \mathrm{mg} 1$ tablet daily at evening for $1^{\text {st }}$ week, 1 tablet at morning and evening for $2^{\text {nd }}$ week, 1 tablet at morning and 2 tablet at evening for $3^{\text {rd }}$ week and then 2 tablet at morning and evening (2 gram per day) upto eight weeks. Group-B patients were treated with $7.5 \mathrm{mg}$ of oral Methotrexate (Methotrax, 2.5mg three tablets) once weekly at night on a definite day. For group B tablet Folic acid (Folison $5 \mathrm{mg}$ ) on the next night (24 hours later) of methotrexate once weekly for total eight weeks duration. No topical medication except bland emollients was applied on the psoriasis plaque. Patient's general physical examination, history and follow-up investigations for assessing adverse side effects were done after 2nd week, 4th week and finally after $8^{\text {th }}$ week of treatment. Follow-up laboratory investigations were: Complete Blood Count (Total and differential count of White blood cell, hemoglobin and ESR), platelet count $\left(\times 10^{9} / \mathrm{L}\right)$, serum alanine transaminase (S. ALT) (U/L)and renal function tests (BUN, creatinine).

\section{Data processing and analysis:}

All collected data were checked and rechecked for omissions, inconsistencies and improbabilities. Data analysis was performed by Statistical Package for Social Science (SPSS), version-16. Data was edited, coded and entered into the computer. Statistical analyses were done and level of significance were measured by using appropriate procedures like chi square test $(\div 2)$, paired and unpaired t-test. Level of significance ( $p$ value) was set at 0.05 and confidence interval at $95 \%$.

\section{Results:}

Table I shows the mean \pm SD age was $34.7 \pm 12.7$ years and $34.5 \pm 15.8$ years in group A and group B respectively. Male was found $7(46.7 \%)$ in group A and $8(53.3 \%)$ in group B. Maximum respondents of both groups were married, which was $11(73.3 \%)$ in group A and $10(66.7 \%)$ in group B. Family history of same disease was found $4(26.7 \%)$ in group A and $1(6.7 \%)$ found in group B. Analysis revealed no significant difference between two groups in terms of age, sex, marital status and family history of same disease.

Regarding the duration of illness, we found that most of the patients suffered 1- 5 years in both groups, which were $8(53.3 \%)$ and $10(66.7 \%)$ in group A and group B respectively. The mean duration of illness was $5.5 \pm 3.7$ years in group A and $4.4 \pm 3.5$ years in group B. There is no statistically significant difference between two groups in terms of duration of illness ( $p$ value $>0.05$ ). The itching status of the study patients was found $13(86.7 \%)$ patients in group A and $10(66.7 \%)$ in group B. There is no statistically significant difference between two groups in terms itching status ( $p$ value $>0.05$ ) 
Table I

Comparison of baseline characteristics of patients of group-A and group- $B$.

\begin{tabular}{|c|c|c|c|c|c|c|}
\hline \multirow[b]{2}{*}{ Age (in year) } & \multicolumn{2}{|c|}{$\begin{array}{c}\text { Group A } \\
(\mathrm{n}=15)\end{array}$} & \multicolumn{2}{|c|}{$\begin{array}{c}\text { Group B } \\
(\mathrm{n}=15)\end{array}$} & \multirow[t]{2}{*}{$\begin{array}{l}\mathrm{t} / \mathrm{chi} \\
\text { value }\end{array}$} & \multirow[t]{2}{*}{$\begin{array}{c}\mathrm{P} \\
\text { value }\end{array}$} \\
\hline & $\mathrm{n}$ & $\%$ & $\mathrm{n}$ & $\%$ & & \\
\hline$<20$ & 1 & 6.7 & 3 & 20.0 & 0.05 & $0.960^{\mathrm{ns}}$ \\
\hline $21-30$ & 7 & 46.7 & 6 & 40.0 & & \\
\hline $31-40$ & 3 & 20.0 & 1 & 6.7 & & \\
\hline $41-50$ & 2 & 13.3 & 1 & 6.7 & & \\
\hline$>50$ & 2 & 13.3 & 4 & 26.7 & & \\
\hline Mean \pm SD & \multicolumn{2}{|c|}{$34.7 \pm 12.7$} & \multicolumn{2}{|c|}{$34.5 \pm 15.8$} & & \\
\hline \multicolumn{7}{|l|}{ Sex } \\
\hline Male & 7 & 46.7 & 8 & 53.3 & 0.13 & $0.715^{\mathrm{ns}}$ \\
\hline Female & 8 & 53.3 & 7 & 46.7 & & \\
\hline \multicolumn{7}{|l|}{ Marital status } \\
\hline Married & 11 & 73.3 & 10 & 66.7 & 0.16 & $0.690^{\text {ns }}$ \\
\hline Unmarried & 4 & 26.7 & 5 & 33.3 & & \\
\hline \multicolumn{7}{|c|}{ Family history of same disease } \\
\hline Yes & 4 & 26.7 & 1 & 6.7 & 2.16 & $0.141^{\mathrm{ns}}$ \\
\hline No & 11 & 73.3 & 14 & 93.3 & & \\
\hline \multicolumn{7}{|c|}{ Duration of Illness (years) } \\
\hline $1-5$ & 8 & 53.3 & 10 & 66.7 & 0.78 & $0.443^{\text {ns }}$ \\
\hline $6-10$ & 6 & 40.0 & 4 & 26.7 & & \\
\hline$>10$ & 1 & 6.7 & 1 & 6.7 & & \\
\hline Mean \pm SD & \multicolumn{2}{|c|}{$5.5 \pm 3.7$} & \multicolumn{2}{|c|}{$4.4 \pm 3.5$} & & \\
\hline \multicolumn{7}{|l|}{ Itching } \\
\hline Present & 13 & 86.7 & 10 & 66.7 & 1.60 & $0.195^{\mathrm{ns}}$ \\
\hline Absent & 2 & 13.3 & 5 & 33.3 & & \\
\hline
\end{tabular}

Group A: Sulfasalazine Group B: Methotrexate $\mathrm{ns}=$ Not significant, $\mathrm{P}$ value reached from unpaired t-test and chi square test.

Table II Comparison of Psoriasis Area and Severity index (PASI) in two groups.

\begin{tabular}{lcccc}
\hline & $\begin{array}{c}\text { Group A } \\
(\mathrm{n}=15) \\
\text { Mean } \pm \text { SD }\end{array}$ & $\begin{array}{c}\text { Group B } \\
(\mathrm{n}=15) \\
\text { Mean } \pm \text { SD }\end{array}$ & $\begin{array}{c}\mathrm{t} \\
\text { value }\end{array}$ & $\begin{array}{c}\text { P } \\
\text { value }\end{array}$ \\
PASI & $14.7 \pm 4.5$ & $12.5 \pm 4.2$ & 1.39 & $0.174^{\text {ns }}$ \\
Base line & $8.8 \pm 2.6$ & $8.1 \pm 3.1$ & 0.73 & $0.468^{\text {ns }}$ \\
After 4 ${ }^{\text {th }}$ week & 39.4 & & 35.4 & \\
Reduction after $4^{\text {th }}$ weeks (\%) & $0.155^{\text {ns }}$ & & & \\
1.46 & $6.0 \pm 2.8$ & $4.5 \pm 1.4$ & 1.81 & $0.082^{\text {ns }}$ \\
After $8^{\text {th }}$ week & 59.6 & 60.7 & -.20 & $0.802^{\text {ns }}$ \\
Reduction after $8^{\text {th }}$ weeks (\%) &
\end{tabular}

Group A: Sulfasalazine, Group B: Methotrexate

ns $=$ Not significant and $P$ value reached from unpaired $t$-test. 
Mean Psoriasis Area and Severity Index (PASI) score of Group A and Group B at baseline was $14.7 \pm 4.5$ and $12.5 \pm 4.2$ and respectively. The mean PASI score after $4^{\text {th }}$ weeks therapy was $8.8 \pm 2.6$ and $8.1 \pm 3.1$ for group A and Group B respectively. After $8^{\text {th }}$ week mean PASI score was $6.0 \pm 2.8$ and $4.5 \pm 1.4$ in group A and group B. The mean difference of PASI at baseline, after $4^{\text {th }}$ week and after 8 weeks of therapy was not statistically significant ( $\mathrm{p}$ value $>0.05$ ) between two groups.

The mean percentage of PASI reduction after $4^{\text {th }}$ week of treatment was 39.4 and 35.4 in group A and group B ( $\mathrm{p}$ value $>0.05$ ). The mean percentage of PASI reduction after $8^{\text {th }}$ week of therapy was 59.6 in-group A and 60.7 in-group $B$ respectively. The mean different was not statistically significant ( $p$ value $>0.05$ ) between both groups.

Table III

Comparison of pulse, BP and temperature of patients at baseline and at follow-up in two groups.

\begin{tabular}{|c|c|c|c|c|}
\hline Variable & $\begin{array}{c}\text { Group A } \\
(\mathrm{n}=15) \\
\text { Mean } \pm \mathrm{SD}\end{array}$ & $\begin{array}{c}\text { Group B } \\
(\mathrm{n}=15) \\
\text { Mean } \pm \text { SD }\end{array}$ & $\begin{array}{c}\mathrm{t} \\
\text { value }\end{array}$ & $\begin{array}{c}\mathrm{P} \\
\text { value }\end{array}$ \\
\hline \multicolumn{5}{|l|}{ Pulse } \\
\hline Base line & $73.6 \pm 10.5$ & $73.6 \pm 8.8$ & 0.00 & $1.000^{\mathrm{ns}}$ \\
\hline $1^{\text {st }}$ follow up & $77.9 \pm 10.2$ & $72 \pm 5.2$ & 1.98 & $0.058^{\text {ns }}$ \\
\hline $2^{\text {nd }}$ follow up & $73.6 \pm 5.2$ & $73.3 \pm 8.4$ & 0.10 & $0.917^{\mathrm{ns}}$ \\
\hline $3^{\text {rd }}$ follow up & $77.6 \pm 9.3$ & $77.1 \pm 6.5$ & 0.18 & $0.857^{\mathrm{ns}}$ \\
\hline
\end{tabular}

Blood pressure (systolic)

$\begin{array}{lcccc}\text { Base line } & 110.3 \pm 12.9 & 111 \pm 16.3 & -.12 & 0.902^{\text {ns }} \\ 1^{\text {st }} \text { follow up } & 111.0 \pm 14.7 & 108.3 \pm 17.6 & 0.45 & 0.655^{\text {ns }} \\ 2^{\text {nd }} \text { follow up } & 117.0 \pm 14.0 & 109.7 \pm 18.2 & 1.24 & 0.226^{\text {ns }} \\ 3^{\text {rd }} \text { follow up } & 113.3 \pm 14.6 & 112.3 \pm 17.8 & 0.17 & 0.868^{\text {ns }}\end{array}$

Blood pressure (diastolic)

$\begin{array}{lcccc}\text { Base line } & 76.0 \pm 8.7 & 73.7 \pm 8.3 & 0.75 & 0.460^{\text {ns }} \\ 1^{\text {st }} \text { follow up } & 76.3 \pm 7.9 & 73 \pm 7 & 1.22 & 0.232^{\text {ns }} \\ 2^{\text {nd }} \text { follow up } & 77.3 \pm 6.2 & 75 \pm 8.7 & 0.85 & 0.404^{\text {ns }} \\ 3^{\text {rd }} \text { follow up } & 76.7 \pm 6.7 & 76 \pm 8.7 & 0.23 & 0.816^{\text {ns }}\end{array}$

Temperature

\begin{tabular}{lllll} 
Base line & $97.9 \pm 0.5$ & $97.8 \pm 0.7$ & 0.43 & $0.672^{\text {ns }}$ \\
$1^{\text {st }}$ follow up & $98.0 \pm 0.7$ & $97.8 \pm 0.6$ & 1.03 & $0.312^{\text {ns }}$ \\
$2^{\text {nd }}$ follow up & $97.9 \pm 0.5$ & $97.5 \pm 0.5$ & 1.93 & $0.064^{\text {ns }}$ \\
$3^{\text {rd }}$ follow up & $97.7 \pm 0.5$ & $97.9 \pm 0.7$ & -.89 & $0.381^{\text {ns }}$ \\
\hline
\end{tabular}

Group A: Sulfasalazine

Group B: Methotrexate

ns=Not significant, $\mathrm{P}$ value reached from unpaired t-test.

Pulse, blood pressurte and temperature changes were almost similar between two groups during baseline and different follow-up. 
Table IV

Comparison of Laboratory reports at baseline and at follow-up in two groups.

\begin{tabular}{|c|c|c|c|c|}
\hline Investigation & $\begin{array}{c}\text { Group A }(n=15) \\
\text { Mean } \pm \text { SD }\end{array}$ & $\begin{array}{c}\text { Group B }(n=15) \\
\text { Mean } \pm \text { SD }\end{array}$ & $\begin{array}{c}\mathrm{t} \\
\text { value }\end{array}$ & $\begin{array}{c}\mathrm{P} \\
\text { value }\end{array}$ \\
\hline \multicolumn{5}{|l|}{$\mathrm{Hb}(\mathrm{gm} / \mathrm{dl})}$. \\
\hline Baseline & $12.3 \pm 1.9$ & $13.2 \pm 1.0$ & -1.64 & $0.111^{\mathrm{ns}}$ \\
\hline $4^{\text {th }}$ weeks & $12.3 \pm 1.5$ & $12.9 \pm 1.0$ & -1.40 & $0.171^{\mathrm{ns}}$ \\
\hline $8^{\text {th }}$ weeks & $12.4 \pm 1.8$ & $13.0 \pm 1.2$ & -1.12 & $0.273^{\text {ns }}$ \\
\hline \multicolumn{5}{|l|}{$\operatorname{ESR}\left(\right.$ in $1^{\text {st }} \mathrm{hr}$. ) } \\
\hline Baseline & $22.7 \pm 18$ & $17.0 \pm 11.9$ & 1.03 & $0.313^{\text {ns }}$ \\
\hline $4^{\text {th }}$ weeks & $23.7 \pm 17.9$ & $17.0 \pm 7.5$ & 1.33 & $0.194^{\mathrm{ns}}$ \\
\hline $8^{\text {th }}$ weeks & $19.1 \pm 15.1$ & $15.3 \pm 8.3$ & 0.85 & $0.401^{\mathrm{ns}}$ \\
\hline \multicolumn{5}{|l|}{$\mathrm{WBC}\left(\times 10^{9} / \mathrm{L}\right)$} \\
\hline Baseline & $9.2 \pm 2.3$ & $9.0 \pm 1.9$ & 0.23 & $0.819^{\text {ns }}$ \\
\hline $4^{\text {th }}$ weeks & $8.1 \pm 1.9$ & $8.9 \pm 1.7$ & -1.25 & $0.222^{\mathrm{ns}}$ \\
\hline $8^{\text {th }}$ weeks & $8.5 \pm 2.3$ & $8.9 \pm 2.3$ & -0.37 & $0.715^{\mathrm{ns}}$ \\
\hline \multicolumn{5}{|c|}{ Platelet count $\left(\left(\times 10^{9} / \mathrm{L}\right)\right)$} \\
\hline Baseline & $276 \pm 62.6$ & $270.7 \pm 54$ & 0.25 & $0.805^{\mathrm{ns}}$ \\
\hline $4^{\text {th }}$ weeks & $273.7 \pm 81.4$ & $274 \pm 52.5$ & -0.01 & $0.989^{n s}$ \\
\hline $8^{\text {th }}$ weeks & $255.6 \pm 36.5$ & $259.1 \pm 45.1$ & -0.24 & $0.815^{\mathrm{ns}}$ \\
\hline \multicolumn{5}{|l|}{ Serum ALT (U/L) } \\
\hline Baseline & $29.5 \pm 11.8$ & $24.1 \pm 10.5$ & 1.33 & $0.195^{\mathrm{ns}}$ \\
\hline $4^{\text {th }}$ weeks & $25.0 \pm 9.1$ & $26.7 \pm 10.5$ & -0.48 & $0.633^{n s}$ \\
\hline $8^{\text {th }}$ weeks & $27.8 \pm 15.2$ & $26.0 \pm 7.3$ & 0.41 & $0.683^{n s}$ \\
\hline
\end{tabular}

Group A: Sulfasalazine Group B: Methotrexate

$\mathrm{ns}=$ Not significant, $\mathrm{P}$ value reached from unpaired t-test.

$\mathrm{Hb} \%$, ESR, total WBC, platelet count and serum ALT change are not statistically significant ( $\mathrm{p}$ value $>0.05$ ) between two groups during baseline, $4^{\text {th }}$ weeks and $8^{\text {th }}$ weeks follow-up.

Table V

Comparison of adverse effects in two treatment groups.

\begin{tabular}{|c|c|c|c|c|c|c|}
\hline \multirow{2}{*}{$\begin{array}{l}\text { Adverse effects of drug and } \\
\text { types of adverse reaction }\end{array}$} & \multicolumn{2}{|c|}{ Group A ( $\mathrm{n}=15)$} & \multicolumn{2}{|c|}{ Group B ( $\mathrm{n}=15)$} & \multirow[t]{2}{*}{ Chi value } & \multirow[t]{2}{*}{$\mathrm{P}$ value } \\
\hline & $\mathrm{n}$ & $\%$ & $\mathrm{n}$ & $\%$ & & \\
\hline Adverse effects present & 11 & 73.3 & 10 & 66.7 & 0.16 & $0.500^{\mathrm{ns}}$ \\
\hline Adverse effects absent & 4 & 26.7 & 5 & 33.3 & & \\
\hline \multicolumn{7}{|l|}{ List of adverse effects } \\
\hline Nausea & 4 & 26.7 & 2 & 13.3 & 0.83 & $0.500^{\mathrm{ns}}$ \\
\hline Vomiting & 4 & 26.7 & 2 & 13.3 & 0.83 & $0.325^{\mathrm{ns}}$ \\
\hline Headache & 0 & 0.0 & 1 & 6.7 & 1.03 & $0.309^{\text {ns }}$ \\
\hline Abdominal pain & 4 & 26.7 & 2 & 13.3 & 0.83 & $0.325^{\mathrm{ns}}$ \\
\hline Mouth ulcer & 1 & 6.7 & 1 & 6.7 & 0.00 & $0.758^{\text {ns }}$ \\
\hline Throat pain & 0 & 0.0 & 1 & 6.7 & 1.03 & $0.500^{\mathrm{ns}}$ \\
\hline Skin rash & 0 & 0.0 & 0 & 0.0 & - & - \\
\hline Anorexia & 1 & 6.7 & 1 & 6.7 & 0.0 & $0.758^{\mathrm{ns}}$ \\
\hline Dysnea & 0 & 0.0 & 0 & 0.0 & - & - \\
\hline Alopecia & 0 & 0.0 & 0 & 0.0 & - & - \\
\hline Vertigo & 2 & 13.3 & 2 & 13.3 & 0.0 & $0.701^{\mathrm{ns}}$ \\
\hline Diarrhoea & 0 & 0.0 & 0 & 0.0 & - & - \\
\hline Fever & 0 & 0 & 2 & 13.3 & 2.14 & $0.241^{\mathrm{ns}}$ \\
\hline Others & 1 & 6.7 & 2 & 13.3 & 0.37 & $0.500^{\mathrm{ns}}$ \\
\hline
\end{tabular}

Group A: Sulfasalazine Group B: Methotrexate

$\mathrm{ns}=$ Not significant, $\mathrm{P}$ value reached from chi square test. 
Table V shows the adverse effects of drug and types of adverse effect. Adverse effects was found $11(73.3 \%)$ respondents in group $A$ and 10 $(66.7 \%)$ in group B. Nausea was found $4(26.7 \%)$ in group A and $2(13.3 \%)$ in group B. Vomiting was found $4(26.7 \%)$ and $2(13.2 \%)$ in group $A$ and group B respectively. Headache was found not found in group A and $1(6.7 \%)$ was fount in group B. Abdominal pain was $4(26.7 \%)$ and $2(13.2 \%)$ in group A and group B respectively. Mouth ulcer was found $1(6.7 \%)$ in group A and $1(6.7 \%)$ in group B. Throat pain was not found in group A and $1(6.7 \%)$ in group B. Anorexia was $1(6.7 \%)$ in group A and $1(6.7 \%)$ in group B respectively. Vertigo was found $2(13.2 \%)$ and $2(13.2 \%)$ in group A and group B respectively. But there is no significant difference in two groups and $2(13.2 \%)$ in group A and group B respectively. Fever was not found in group A and $2(13.2 \%)$ in group B. Others was found $1(6.7 \%)$ and $2(13.2 \%)$ in group A and group B respectively.

Skin rush, dysnea and diarrhoea was not found in both groups. Adverse effects of drug, nausea, vomiting, headache, abdominal pain, mouth ulcer, throat pain, anorexia, vertigo, fever and others was not statistically significant ( $p$ value $>0.05$ ) between two groups.

\section{Discussion:}

The current study was conducted to evaluate the safety of sulfasalazine in the treatment of chronic plaque type psoriasis. It was carried out in the department of Dermatology and Venereology, Bangabandhu Sheikh Mujib Medical University, Shahabagh, Dhaka during the period of April 2010 to may 2011, over randomly selected thirty patients with clinically and histopathologicaly diagnosed chronic plaque type psoriasis. Among them 15 were (Group A) treated with Sulfasalazine 2 gram ( Reumazin 500mg 4 tablets in two divided dose ) and another 15 were (Group B) treated with Methotrexate $7.5 \mathrm{mg}$ (Methotrax $2.5 \mathrm{mg} 3$ tablet ) with folic acid supplement (folison $5 \mathrm{mg}$ ).

Mean age of the study subjects were $34.60 \pm 14.08$ years with a range 47 years (1360 years), $70.0 \%$ of patients were in the age group up to 40 years (Type-I psoriasis), which is very close to the finding of a large epidemiological study by Langely et al. who found $75 \%$ in Type- 1 psoriasis. ${ }^{7}$ Current study showed that both sexes affected equally (male $=$ female $=15$ ). This finding is similar with the observation by Christopher in 2006, and Farber and Nall in 1974, which stated that there is no phenotypically difference between the sexes. 8,9

Only $16.66 \%$ patients gave positive family history of psoriasis that is highly apart from the report of most important field study of psoriasis in Faroe Island by Lomholt who found positive family history in about $91 \%$ respondents. ${ }^{8}$ This difference may be due to small homogenous population of Faroe Island. Both our finding and Lomholt's result is covered by the study of prevalence of psoriasis in Spain. who stated that familial occurrence vary from $4.4 \%$ to $90.9 \% .^{10}$

Itching was a presenting complaint in $86.7 \%$ of group A patients, $66.7 \%$ of group B patients and in overall $76.7 \%$ patients. In different earlier studies, itching was very variable from complete absence to severe in minority of patients. ${ }^{11}$ Newbold reported that $92 \%$ consecutive patients hospitalized with psoriasis had occasional pruritus and Gupta et al. reported that $67 \%$ hospitalized psoriasis patients complained of moderate or severe pruritus. ${ }^{12,13}$ In our study $23.3 \%$ patients were asymptomatic. We did not consider pruritus as an outcome measure in our study, as the grading of pruritus is difficult owing to the purely subjective nature of this parameter.

Mean Psoriasis Area and Severity Index (PASI) score of Group A and Group B at baseline was $14.7 \pm 4.5$ and $12.5 \pm 4.2$ respectively $(p=0.174)$. The mean PASI after 4 weeks therapy was 8.8 \pm 2.6 and $8.1 \pm 3.1$ for Group A and Group B respectively $(\mathrm{p}=0.468)$. After 8 weeks of therapy mean PASI score was $6.0 \pm 2.8$ and $4.5 \pm 1.4$ for Group A and Group B respectively ( $\mathrm{p}=0.082)$. The mean percentage of improvement of psoriasis, based on reduction of PASI at final follow up (after 8 weeks) was $59.6 \pm 9.6$ and 60.7 \pm 13.2 in Group A and Group B respectively $(p=0.802)$.There were no significant differences in PASI score and PASI reduction percentage at base line, after $4^{\text {th }}$ and $8^{\text {th }}$ week of therapy in two groups (A \& B). Our study 
design and findings are much closer to the study carried out by Bharti and Girgla in respect of study design. They compared the efficacy of Sulfasalazine to methotrexate in psoriasis, efficacy was comparable for the 2 drugs after 12 weeks trial. ${ }^{14}$ In another earlier study, Gupta et al, carried out an 8-week double-blind trial of sulfasalazine for the treatment of moderate-to-severe psoriasis, considering its low incidence of severe side effects, recommended sulfasalazine a consideration for oral therapy in patients whose disease severity does not justify use of methotrexate, etretinate, or psoralen plus UV-A, but whose disease severity is too widespread for safe and practical use of topical corticosteroids.${ }^{15}$ A double blind trial by Menne et al of 5 am-inosalicylic acid in cream base and an open study of oral sulfasalazine indicate that both of these lipoxygenase inhibitors may be effective in psoriasis treatment. ${ }^{16}$

El-Mofty et al, carried out a comparative trial on chronic plaque type psoriasis with sulfasalazine, pentoxiphylline, combined sulfasalazine and pentoxiphylline and methotrexate in four groups of patients for 8 weeks. The mean percentage of PASI score reduction was $57.09 \pm 8.07$ in sulfasalazine group and $80.95 \pm 9.4$ in methotrexate group with significant difference $(\mathrm{p}=0.006) .{ }^{17}$

There is strong evidence demonstrating that $50 \%$ improvement in PASI (PASI 50) is clinically meaningful endpoint.$^{18}$ In our study $86.66 \%$ participants of both group achieved PASI 50 after 8 weeks. As previous studies of Sulfasalazine by Menne et al, Gupta et al, Bharti and Girgla, did not use PASI as an outcome measure, we can not compare our outcomes with them. ${ }^{16,15,14}$ Moreover, Bharti and Girgla used topical steroid to both groups, which might modify the outcome of systemic drugs. ${ }^{14}$ El-Mofty et al. used PASI as final outcome in their study. ${ }^{17}$ Among the four groups of their study the end results of sulfasalazine group was near to us but that of methotrexate group was different. This difference might be dose dependant because they use oral methotrexate $25 \mathrm{mg}$ weekly but we used $7.5 \mathrm{mg}$ in a week.
Flytström et al found 58\% PASI reduction with $15 \mathrm{mg}$ weekly methotrexate, which was comparable $(60 \%)$ with our study. ${ }^{19}$ We found that both the drugs are effective in chronic plaque type psoriasis. Adverse effect of drug were noticed $73.3 \%$ in group A and $66.7 \%$ in group $B(p=0.500)$. Nausea, vomiting, abdominal pain, and vertigo were the common adverse effects in both groups. However, they were mild to moderate in severity and did not require stop of therapy statistical differences were nonsignificant in two groups.

There was no significant difference in $\mathrm{Hb}$ percentage, ESR, total WBC count, Platelet count and serum alanine transaminase (ALT) between two groups at baseline and after $4^{\text {th }}$ and $8^{\text {th }}$ week of therapy. None of adverse effects of MTX in our series was serious, Whereas Saurat et al. reported adverse effects in $81.8 \%$ among 110 cases treated with Methotrexate and only $0.1 \%$ of them were severe. ${ }^{20}$ The higher rate of adverse effects in their study may be due to higher dose (up to $25 \mathrm{mg}$ weekly) and longer duration of treatment (16 weeks). No adverse effect was reported by Bharti and Girgla in sulfasalazine and methotrexate group. ${ }^{14} \mathrm{El}-$ Mofty et al. reported adsverse effects in only $23 \%$ patients of all 4 groups in which nausea was the commonest side effect of sulfasalazine group. ${ }^{17}$

Flytström et al reported adverse effects of methotrexate in $78 \%$ of participants where gastrointestinal side effects were common. ${ }^{19}$ So, considering comparable efficacy of sulfasalazine (Reumazine) with methotrexate (Methotrax) and reasonable adverse effects we recommend it as an alternative treatment option for chronic plaque type psoriasis.

\section{Conclusion:}

In the light of this research work, we recommend that sulfasalazine can be tried before treating with other harmful and costly antipsoriatics. Long term and large-scale studies should be carried out to evaluate the long-term efficacy, post treatment relapse and safety of sulfasalazine in chronic plaque psoriasis. 


\section{References:}

1. Reich K, Mrowietz U. Treatment goals in psoriasis. $\mathrm{J}$ Deutschen Dermatologischen Gesellschaft 2007; 5(7): 566-74.

2. Hawkey CJ, Truelove SC. Inhibition of prostaglandin synthetase in human rectal mucosa. Gut 1983; 24: 213-7.

3. Stenson WF, Lobos E. Sulfasalazine inhibits the synthesis of chemotactic lipids by neutrophils. J Clin Invest 1982; 69: 494-7.

4. Gadangi $P$, Longaker M, Naime D, Levin RI, Recht PA. The anti-inflammatory mechanism of sulfasalazine is related to adenosine release at inflamed sites. J Immunol 1996; 156: 1937-41.

5. Naldi L, Griffiths CEM. Traditional therapies in the management of moderate to severe chronic plaque psoriasis: an assessment of the benefits and risks. Br J Dermatol 2005; 52(3): 597-615.

6. Kevin RS, Daniel JP, Steven RF. Targeted UV therapy in the treatment of psoriasis. Journal of Dermatolog Treat 2008; 19(3): 141-5.

7. Langely R, Krueger G, Griffiths C. Psoriasis: epidemiology, clinical features, and quality of life. Ann Rheum Dis 2005; 64(Suppl 2): 18-23.

8. Christophers E. Comorbidities in psoriasis. J Eur Acad Dermatol Venereol 2006; 20(2): 52-5.

9. Farber EM, Nall L. The natural history of psoriasis in 5600 patients. Dermatologica 1974 ; 148: 118.

10. Gelfand JM, Gladman DD, Mease PJ, Smith N, Margolis DJ, Nijsten, T. Epidemiology of psoriatic arthritis in the population of the United States. J Am Acad Dermatol 2005; 53(4): 573-7.

11. Griffiths CEM, Camp RDR, Barker JNWN. Psoriasis. In: Burns T, Breathnach S, Cox N, Griffiths C. eds. Rook's Textbook of Dermatology, $7^{\text {th }}$ ed. Masachusetts: Blackwell publisher; 2004.

12. Newbold PCH. Pruritus in psoriasis. In: Farber EM, Cox AJ. eds. Psoriasis: Proceedings of the Second International Symposium. New York: York Medical Books; 1977. pp.334-6.
13. Gupta MA, Gupta AK, Kirby S. Pruritus in psoriasis. A prospective study of some psychiatric and dermatologic correlates. Arch Dermatol 1988; 24: 1052-7.

14. Bharti R, Girgla SP. Sulfasalazine in treatment of psoriasis. Indian J Dermatol Venereol Leprol 1996; 62(2): 87-8.

15. Gupta AK, Ellis CN, Siegel MT, Duell EA, Griffiths CEM, Hamilton TA. Sulfasalazine improves psoriasis. Arch Dermatol 1990; 126(4): 487-93.

16. Menné T, Larsen U, Veien N, Klemp P, Branebjerg PE. 5 aminosalicylic acid in a cream base improves psoriasis - a double blind study. J Dermatolg Treat 1989; 1(1): 5-7.

17. El-Mofty M, El-Darouti M, Rasheed H, Bassiouny DA, Abdel-Halim M, Zaki NS, et al. Sulfasalazine and pentoxifylline in psoriasis: a possible safe alternative. J Dermatolg Treat 2011; 22(1): 31-7.

18. Carlin CS, Feldman SR, Cruger JG, Menter A. A $50 \%$ reduction in the psoriasis area and severity index (PASI 50) is a clinically significant endpoint in the assessment of psoriasis. J Am Acad Dermatol 2004; 50(6): 859-66.

19. Flytstrom I, Stenberg B, Svensson A, Bergbrant IM. Methotrexate vs. ciclosporin in psoriasis: effectiveness, quality of life and safety - a randomized controlled trial. Br J Dermatol 2007; 51: $116-21$.

20. Saurat JH, Sting G, Dubertret L, Papp K, Langley RG, Ortonne JP. Efficacy and safety results from the randomized controlled comparative study of adalimumab vs. methotrexate vs. placebo in patients with psoriasis. Br J Dermatol 2008; 158(3): $558-56$

21. Tan JK, Aphale, A Malaviya R, Sun Y, Gottlieb AB. Mechanisms of action of etanercept in psoriasis. J Invest Dermatol Symp Proc 2007; 12(1): 38-45.

22. Thaci D. Long-term data in the treatment of psoriasis. Br J Dermatol 2008; 159(2): 18-24. 